\title{
CNS manifestations in patients with telomere biology disorders
}

Sonia Bhala, BS, Ana F. Best, PhD, Neelam Giri, MD, Blanche P. Alter, MD, MPH, Maryland Pao, MD, Andrea Gropman, MD, Eva H. Baker, MD, PhD, and Sharon A. Savage, MD

Neurol Genet 2019;5:e370. doi:10.1212/NXG.0000000000000370

\section{Abstract}

\section{Objective}

We systematically evaluated CNS manifestations in patients with inherited telomere biology disorders (TBDs) to better understand the clinical and biological consequences of germline aberrations in telomere biology.

\section{Methods}

Forty-four participants with TBDs (31 dyskeratosis congenita, 12 Hoyeraal-Hreidarsson syndrome, and 1 Revesz syndrome) enrolled in an institutional review board-approved longitudinal cohort study underwent detailed clinical assessments, brain MRI, and genetic testing. Lymphocyte telomere length Z-scores were calculated to adjust for age.

\section{Results}

In this cohort, 25/44 (57\%) patients with a TBD had at least 1 structural brain abnormality or variant, most commonly cerebellar hypoplasia (39\%). Twenty-one patients (48\%) had neurodevelopmental disorder or psychomotor abnormality. Twelve had psychiatric diagnoses, including depression and/or anxiety disorders. Other findings such as hypomyelination, prominent cisterna magna, and cavum septum pellucidum were more frequent than in the general population $(p<0.001)$. Shorter lymphocyte telomere length was associated with an increased number of MRI findings $(p=0.02)$ and neurodevelopmental abnormalities $(p<0.001)$. Patients with autosomal recessive or X-linked TBDs had more neurologic findings than those with autosomal dominant disease.

\section{Conclusions}

Structural brain abnormalities and variants are common in TBDs, as are neurologic and psychiatric symptoms. The connection between neurodevelopment and telomere biology warrants future study.

\author{
Correspondence \\ Dr. Savage \\ savagesh@mail.nih.gov
}




\section{Glossary}

$\mathbf{A D}=$ autosomal dominant; $\mathbf{A R}=$ autosomal recessive $; \mathbf{B M F}=$ bone marrow failure; $\mathbf{C I}=$ confidence interval; $\mathbf{D C}=$ dyskeratosis congenita; DSM = Diagnostic and Statistical Manual of Mental Disorders; FISH = fluorescence in situ hybridization; IUGR = intrauterine growth restriction; $\mathbf{O R}=$ odds ratio; $\mathbf{R S}=$ Revez syndrome; $\mathbf{T B D}=$ telomere biology disorder; $\mathbf{X L R}=\mathrm{X}$-linked recessive.

Telomere biology disorders (TBDs) comprise a spectrum of illnesses caused by pathogenic germline variants in telomere biology genes resulting in very short telomeres. ${ }^{1-3}$ Dyskeratosis congenita (DC) is the prototypic TBD characterized by the mucocutaneous triad of reticulate skin pigmentation, nail dystrophy, and oral leukoplakia. Patients with DC have high rates of bone marrow failure (BMF), cancer, pulmonary disease, liver fibrosis, and other medical problems. ${ }^{1-4}$ Subsets of DC include Hoyeraal-Hreidarsson (HH) syndrome with associated cerebellar hypoplasia, microcephaly, neurodevelopmental disorder, intrauterine growth restriction (IUGR), and immune deficiency and Revez syndrome (RS), which involves bilateral exudative retinopathy, intracranial calcifications, neurodevelopmental disorder, and IUGR. While DC usually manifests in childhood, adult-onset TBDs occur often with isolated aplastic anemia or pulmonary fibrosis.

Very short lymphocyte telomeres for age measured by flow fluorescence in situ hybridization (flow FISH) are diagnostic of DC/TBDs. ${ }^{5}$ Pathogenic germline variants in at least 14 telomere biology genes have been implicated in TBD pathogenesis: autosomal dominant (AD) (TERT, TERC, RTEL1, PARN, TINF2, ACD, and NAF1), autosomal recessive (AR) (TERT, RTEL1, PARN, ACD, CTC1, WRAP53, NOP10, NHP2, POT1, and STN), and X-linked recessive (XLR) (DKC1) inheritance. ${ }^{1-3}$ About $70 \%$ of patients with classic DC have a known genetic cause. ${ }^{1-3}$

Previous studies suggest that $10 \%-50 \%$ of patients with DC have CNS involvement. ${ }^{6-8}$ In this study, we systematically evaluated patients with TBDs who underwent brain MRIs and neurologic and psychiatric evaluations to better understand the CNS manifestations of aberrant telomere biology.

\section{Methods}

\section{Standard protocol approvals, registrations, and patient consents}

Individuals in this study were participants in the National Cancer Institute's Institutional Review Board-approved longitudinal cohort study "Etiologic Investigation of Cancer Susceptibility in Inherited Bone Marrow Failure Syndromes" (NCT-00027274, marrowfailure.cancer.gov, ${ }^{9,10}$ ). All patients or their legal guardians provided written informed consent.

\section{Study participants and clinical evaluations}

We evaluated 44 patients, from 36 families, with $\mathrm{DC}, \mathrm{HH}$, or RS including 26 children and 18 adults. Adults were defined as individuals who were aged 18 years or older on the date of their MRI. Regardless of their symptoms, all patients in this report underwent complete physical examination, and neurologic and psychiatric assessments conducted and/or reviewed by the authors at the NIH Clinical Center between 2001 and 2015. They also underwent a brain MRI, which was performed and/or interpreted at the NIH Clinical Center.

Brain MRIs from both NIH $(\mathrm{n}=31)$ and other institutions $(\mathrm{n}=13)$ were reviewed by the neuroradiologist (E.H.B.). Structural abnormalities and minor variations were recorded. Findings we considered to be abnormalities included cerebellar hypoplasia, delayed myelination, white matter lesions, moderate or marked prominence of the cisterna magna, atrophy, and hypoplasia of the corpus callosum. Findings we considered to be minor variations included mild prominence of the cisterna magna, cavum septum pellucidum and/or cavum vergae, intraparenchymal cysts, and localized prominence of portions of the lateral ventricles (minor colpocephaly). In differentiating cerebellar atrophy from cerebellar hypoplasia, we considered it to be atrophy if the sulci were more prominent than normal, whereas the absence or disproportionately small size of part or all of the cerebellum without prominent sulci was considered to be hypoplasia; in some cases, both findings were present. Delayed myelination could only be evaluated in the youngest children in the study group.

Neurologic findings were divided into 2 categories: neurodevelopmental disorder that included speech and language delay, learning difficulties, and severe neurodevelopmental disorder, or neuromotor findings including difficulties with speech articulation, ataxia, incoordination, and/or an abnormal gait. Microcephaly was defined as head circumference less than the 5th percentile for age per Centers for Disease Control guidelines ${ }^{11}$ and analyzed as an independent category. The presence of a Diagnostic and Statistical Manual of Mental Disorders (DSM)-IV $V^{12}$ (evaluations before 2013) or DSM- ${ }^{13}$ (evaluations after 2013) psychiatric diagnosis was also assessed as its own category. Ten of the patients included in this study were also included in our previous study. ${ }^{8}$

Flow FISH lymphocyte telomere length was measured in 41 patients as part of the diagnostic workup for DC; 3 patients did not have telomere length test results available. Lymphocyte telomere length was adjusted for age by calculating Z-scores. ${ }^{14}$ The degree of BMF was classified as severe, moderate, or none 
by standard definitions. ${ }^{5}$ Three patients underwent hematopoietic cell transplantation before their MRI and clinical evaluation at the NIH Clinical Center. Clinical genetic testing identified the causative gene in 38 of the 44 patients (table 1). Patients with $\mathrm{HH}$ and $\mathrm{RS}$, indicated as $\mathrm{HH} / \mathrm{RS}$, were combined for analyses. We grouped patients by gene and inheritance patterns (XLR/AR, $A D$, and TINF2) as previously described. ${ }^{15}$

\section{Statistical methods}

The correlations between clinical findings were tested with the Pearson correlation coefficient. Fisher exact tests were used to compare the relative prevalence of features across inheritance pattern groups, as well as between our cohort and previously reported incidental findings in a healthy pediatric population. ${ }^{16}$ Binomial logistic regression models were used to compare other clinical features with number of MRI structural, neurologic, and psychiatric abnormalities. Linear regression models were used to determine effect size between telomere length Z-scores and the number of MRI/neurologic abnormalities. We controlled for sex, age, and/or inheritance pattern in these analyses, based on the finding(s) being evaluated. Inheritance patterns considered were XLR, $A D$, and AR. Statistical analysis was performed with $\mathrm{R}$ Version 3.4.0 and the Excel Analysis ToolPak (Microsoft Office 2017).

\section{Results}

\section{Patient demographics}

The characteristics of the study participants are shown in table 1. Thirty-one individuals had clinical DC, 12 had $\mathrm{HH}$, and 1 had RS. There were 6 sibling pairs. Two of these siblings also had an affected parent. Patient age at the time of brain MRI ranged from 1 to 60 years (median 15 years) and was skewed toward younger ages $(p=0.004)$ with $59 \%$ pediatric patients.

Table 1 Clinical and genetic characteristics of study participants

\begin{tabular}{|c|c|c|c|c|c|}
\hline Characteristics $(n=44)$ & Total $(n=44)$ & XLR/AR $(n=18)$ & TINF2 ( $(\mathrm{n}=9)$ & $A D(n=11)$ & Unknown $(n=6)$ \\
\hline \multicolumn{6}{|l|}{ Age $(y)$ at MRI } \\
\hline Median & 15 & 14 & 9 & 18 & 15 \\
\hline Range & $1-60$ & $2-46$ & $1-24$ & $1-60$ & $6-31$ \\
\hline \multicolumn{6}{|l|}{ Age group (y) } \\
\hline $0-9$ & 16 & 6 & 5 & 3 & 2 \\
\hline $10-17$ & 10 & 4 & 1 & 3 & 2 \\
\hline $18-29$ & 11 & 6 & 3 & 1 & 1 \\
\hline $30+$ & 7 & 2 & 0 & 4 & 1 \\
\hline \multicolumn{6}{|l|}{ Sex } \\
\hline Male & 33 & 17 & 8 & 5 & 3 \\
\hline Female & 11 & 1 & 1 & 6 & 3 \\
\hline \multicolumn{6}{|l|}{ Telomere biology disorder } \\
\hline Dyskeratosis congenita & 31 & 11 & 7 & 7 & 6 \\
\hline HH syndrome & 12 & 9 & 1 & 2 & 0 \\
\hline Revesz syndrome & 1 & 0 & 1 & 0 & 0 \\
\hline \multicolumn{6}{|l|}{ Bone marrow failure } \\
\hline None & 9 & 3 & 1 & 2 & 3 \\
\hline Mild or moderate & 9 & 3 & 1 & 3 & 2 \\
\hline Severe & 26 & 12 & 7 & 6 & 1 \\
\hline \multicolumn{6}{|l|}{ Number of triad features } \\
\hline $0-1$ & 14 & 5 & 1 & 6 & 2 \\
\hline $2-3$ & 30 & 13 & 8 & 5 & 4 \\
\hline
\end{tabular}

Abbreviations: AR = autosomal recessive due to pathogenic variants in RTEL1, PARN, ACD, TERT, or WRAP53. AD = autosomal dominant due to pathogenic variants in TERT, TERC, or RTEL1; HH = Hoyeraal-Hreidarsson; XLR = X-linked recessive inheritance due to pathogenic variants in DKC1.

Parenthesis indicates percent of total with specified inheritance pattern (\%). TINF2 is AD; 6 cases of de novo TINF2 mutations were included, and 3 cases were inherited. 
The TBD-associated pathogenic germline variant was known in 38 of 44 patients and included TINF2, DKC1, TERT, TERC, RTEL1, PARN, ACD, and WRAP53.

\section{Structural brain abnormalities and variants}

One or more brain MRI abnormalities were present in 25 of the 44 patients (57\%) (table 2, figure 1). The maximum number of abnormal findings on brain MRI was 4 , seen in 3 patients with DC. All 3 of these patients possessed a recessive genotype and presented with severe BMF. Seventeen patients had cerebellar hypoplasia, 8 had cerebral atrophy, 8 had periventricular cysts, and 7 had a corpus callosum abnormality. In 10 patients with cerebellar hypoplasia, cerebellar atrophy was also noted. Five of the 17 patients with cerebellar hypoplasia had a small pons. Delayed myelination could not be assessed in all the patients because of the cross-sectional nature of the study; however, 6 patients between the ages 1.2-6.5 years (median 3.6 years) had findings consistent with delayed myelination.

Brain MRI findings were correlated with the number of other TBD-related features. Patients with a higher number of MRI findings were more likely to have shorter telomeres than those with a lower number or no findings $(p=0.02)$ (figure 2). The $\mathrm{XLR} / \mathrm{AR}$ inheritance patterns had higher frequencies of cerebellar hypoplasia than all other inheritance patterns combined (odds ratio $[\mathrm{OR}]=6.6,95 \%$ confidence interval $[\mathrm{CI}]$ 1.71-30.96, $p=0.009$ ), after controlling for sex and age group (pediatric vs adult). Those with severe BMF had higher frequencies of cerebellar hypoplasia $(\mathrm{OR}=13.35,95 \% \mathrm{CI}$ 2.46-111.68, $p=0.006)$ than patients with nonsevere or no BMF, controlling for sex and inheritance pattern. Patients with severe BMF also had higher frequencies of MRI findings $(\mathrm{OR}=8.4,95 \% \mathrm{CI} 3.12-27.80, p=0.001)$ than those with nonsevere BMF.

Several brain MRI findings in our patients occurred at much higher frequencies than found incidentally in a general pediatric population. ${ }^{16}$ The statistically significant $(p<0.001)$ findings included higher frequencies of corpus callosum abnormalities, prominent cisterna magna, white matter lesions, and cavum septum pellucidum, and/or cavum vergae variants (table 3). Twenty patients in our study had minor colpocephaly.

\section{Microcephaly}

Microcephaly (head circumference $<5$ th percentile) was present in 17 of 44 patients (table 2, figure 3 ). The median head circumference for all patients, adjusted for age and sex, was at the 29th percentile. Our data showed a bimodal distribution of head circumference, suggesting that head circumference was either severely affected or unaffected. Fourteen of the 17 patients with microcephaly had head circumferences at or below the 1st percentile. Patients with microcephaly had significantly shorter telomeres than those without microcephaly $(p=0.002)$. Pediatric patients had a higher frequency of microcephaly than adult patients $(\mathrm{OR}=$
4.50, 95\% CI 1.15-21.1, $p=0.04$ ) after controlling for sex and inheritance pattern. Patients with HH/RS had a higher frequency of microcephaly than patients with clinical DC (OR = 9.24, 95\% CI 1.98-55.02, $p=0.01$ ), after controlling for age, sex, and inheritance pattern.

\section{Neurologic findings}

Neurologic abnormalities were present in $21 / 44$ patients (table 2). Nineteen had neurodevelopmental disorder. There were 16 patients with impaired neuromotor functioning, such as abnormal gait (15/44), dysarthria (14/44), incoordination $(13 / 44)$, and ataxia $(12 / 44)$. Pediatric patients were more likely to have neuromotor impairments than adult patients ( $\mathrm{OR}=10.2,95 \% \mathrm{CI} 2.20-68.1, p=0.007)$. Patients with HH/ RS were more likely to have neurodevelopmental disorder $(\mathrm{OR}=20.5,95 \%$ CI 2.1-621.2, $p=0.025)$ and neuromotor impairment $(\mathrm{OR}=32.2,95 \%$ CI 5.8-283.7, $p=0.0003)$ than patients with DC. Although all patients with DC had short telomeres, those with neurodevelopmental disorder, neuromotor impairment, and higher numbers of neurologic findings overall had much shorter telomeres than patients without these features $(p=0.005, p=0.004$, and $p \leq 0.001$, respectively) (figure 1B). Patients with AR/XLR pathogenic variants were more likely to have neurologic findings than those with $\mathrm{AD}$ disease $(p=0.03)$. Those with severe BMF had a significantly higher frequency of neurodevelopmental disorder than patients with nonsevere or no BMF ( $O R=10.6$, 95\% CI 1.81-97.03, $p=0.02$ ) and tended to have a higher frequency of neuromotor impairment $(\mathrm{OR}=5.5,95 \% \mathrm{CI}$ $1.19-32.73, p=0.04$ ).

\section{Psychiatric findings}

A clinically significant psychiatric diagnosis was identified in 12 of 44 patients. The majority of the psychiatric diagnoses were mood disorders in adults with depression $(n=6)$ and/or anxiety/panic attacks $(\mathrm{n}=3)$, autism spectrum disorder $(\mathrm{n}=$ $2)$, and bipolar disorder $(n=1)$. The frequency of psychiatric findings was similar between the inheritance patterns (table 2).

\section{Overall}

Microcephaly was associated with an increased number of structural MRI findings $(r=0.42, p=0.004)$. Microcephaly and cerebellar hypoplasia strongly correlated with neurodevelopmental disorder $(\mathrm{r}=0.62, p<0.0001)$ and neuromotor deficits $(\mathrm{r}=0.7, p<0.001)$ such as ataxia, incoordination, and dysarthria. Five of 17 patients with cerebellar hypoplasia did not present with neuromotor cerebellar findings. Of these 5, 3 did not present with neurodevelopmental disorder either and were considered neurologically asymptomatic. Abnormal CNS findings were primarily seen in the pediatric patients with severe BMF who had the shortest telomeres and were also associated with XLR/AR inheritance or TINF2 variants. Four of the 6 sibling pairs with XLR/AR disease (DKC1 and RTEL1) had overlapping CNS features including abnormal MRIs and neurodevelopmental disorder. No CNS abnormalities were present 
Table 2 CNS findings by age and mode of inheritance in patients with TBDs

\begin{tabular}{|c|c|c|c|c|c|c|c|c|c|c|c|}
\hline & \multicolumn{2}{|l|}{ XLR or AR } & \multicolumn{2}{|l|}{ TINF2 } & \multicolumn{2}{|l|}{$A D$} & \multicolumn{2}{|c|}{ Gene unknown } & \multicolumn{3}{|l|}{ All TBDs } \\
\hline & $\begin{array}{l}\text { Children } \\
(n=11)\end{array}$ & $\begin{array}{l}\text { Adults } \\
(\mathrm{n}=9)\end{array}$ & $\begin{array}{l}\text { Children } \\
(n=6)\end{array}$ & $\begin{array}{l}\text { Adults } \\
(\mathrm{n}=3)\end{array}$ & $\begin{array}{l}\text { Children } \\
(n=4)\end{array}$ & $\begin{array}{l}\text { Adults } \\
(n=5)\end{array}$ & $\begin{array}{l}\text { Children } \\
(n=4)\end{array}$ & $\begin{array}{l}\text { Adults } \\
(\mathrm{n}=2)\end{array}$ & $\begin{array}{l}\text { Children } \\
(n=26)\end{array}$ & $\begin{array}{l}\text { Adults } \\
(n=18)\end{array}$ & $\begin{array}{l}\text { Total } \\
(n=44)\end{array}$ \\
\hline MRI abnormalities ${ }^{a, b, c}$ & $9(82)$ & $5(56)$ & $4(67)$ & 0 & $2(50)$ & $3(60)$ & $1(25)$ & $1(50)$ & $16(62)$ & $9(50)$ & $25(57)$ \\
\hline $\begin{array}{l}\text { Cerebellar hypoplasia } \\
\text { or atrophy }\end{array}$ & $8(73)$ & $4(44)$ & 0 & 0 & $2(50)$ & $1(20)$ & $1(25)$ & $1(50)$ & $11(42)$ & $6(33)$ & $17(39)$ \\
\hline Cerebral atrophy & $2(18)$ & $3(33)$ & $1(17)$ & 0 & 0 & $2(40)$ & 0 & 0 & $3(12)$ & $5(28)$ & $8(18)$ \\
\hline Periventricular cysts & $2(18)$ & $1(11)$ & $3(50)$ & 0 & 0 & $1(20)$ & $1(25)$ & 0 & $6(23)$ & $2(11)$ & $8(18)$ \\
\hline $\begin{array}{c}\text { Corpus callosum } \\
\text { abnormalities }\end{array}$ & $3(27)$ & $1(11)$ & $3(50)$ & 0 & 0 & 0 & 0 & 0 & $6(23)$ & $1(6)$ & $7(16)$ \\
\hline Small pons & $2(18)$ & 0 & $1(17)$ & 0 & $2(50)$ & 0 & 0 & 0 & $5(19)$ & 0 & $5(11)$ \\
\hline Neurologic & $10(90)$ & $4(44)$ & $4(67)$ & 0 & $2(50)$ & 0 & $1(25)$ & 0 & $17(65)$ & $4(22)$ & $21(48)$ \\
\hline $\begin{array}{l}\text { Neurodevelopmental } \\
\text { disorder }\end{array}$ & $10(90)$ & $4(44)$ & $3(50)$ & 0 & $2(50)$ & 0 & 0 & 0 & $15(58)$ & $4(22)$ & $19(43)$ \\
\hline Neuromotor & $8(73)$ & $2(22)$ & $3(50)$ & 0 & $2(50)$ & 0 & $1(25)$ & 0 & $14(54)$ & $2(11)$ & $16(36)$ \\
\hline Psychiatric & $1(9)$ & $5(56)$ & $1(17)$ & $1(33)$ & $1(25)$ & $2(40)$ & $1(25)$ & 0 & $4(15)$ & $8(44)$ & $12(27)$ \\
\hline $\begin{array}{l}\text { Depression, anxiety, OCD, } \\
\text { ADHD, or bipolar disorder }\end{array}$ & $1(9)$ & $5(56)$ & $1(17)$ & $1(33)$ & $1(25)$ & $1(20)$ & $1(25)$ & 0 & $4(15)$ & 7 (39) & $11(25)$ \\
\hline Autism & $1(9)$ & $1(11)$ & 0 & 0 & 0 & 0 & 0 & 0 & $1(4)$ & $1(6)$ & $2(5)$ \\
\hline Substance abuse & 0 & $1(11)$ & 0 & 0 & 0 & $1(20)$ & 0 & 0 & 0 & $2(11)$ & $2(5)$ \\
\hline Microcephaly & $7(64)$ & $3(33)$ & $3(50)$ & 0 & $2(5)$ & $0(0)$ & $1(25)$ & $1(50)$ & $13(50)$ & $4(22)$ & $17(39)$ \\
\hline
\end{tabular}

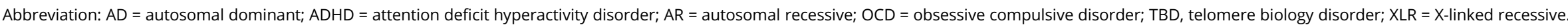
Values in parentheses represent percentages and may not equal $100 \%$ due to rounding.

a One patient with inferior cerebellar vermis hypoplasia also had an abnormal (not delayed) myelination pattern and discrete areas of white matter encephalomalacia (unknown etiology).

b One patient with a small splenium of the corpus callosum also had a potential hamartoma or low-grade glioma in the thalamus and clustered cysts adjacent to the ventricular trigones.

cOne patient had Type I Chiari malformation. 


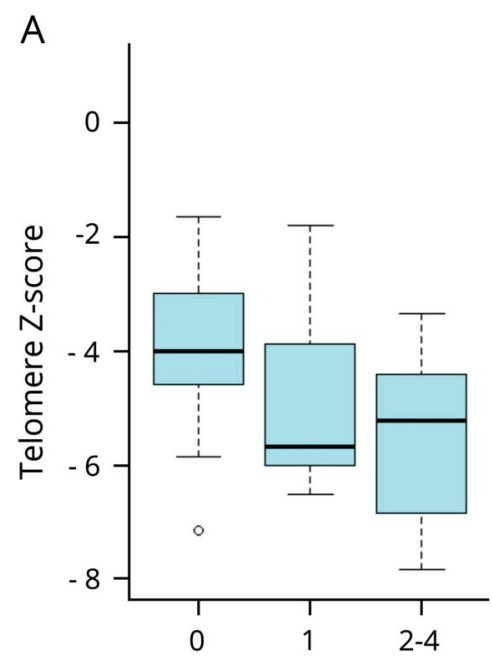

Number of MRI findings
B

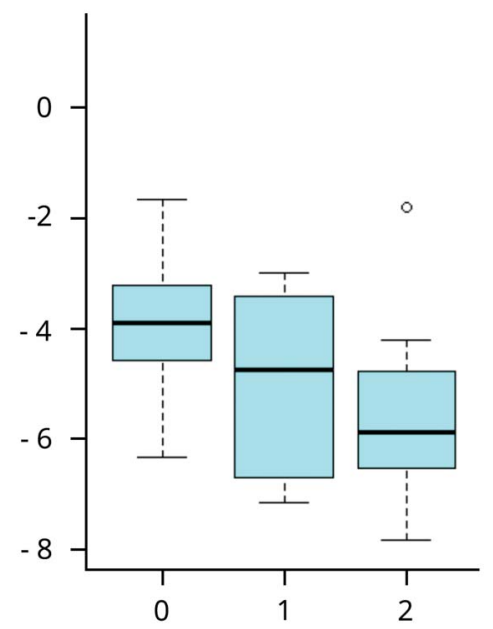

Number of neurologic findings
(A) The number of structural abnormalities on brain MRI and telomere length Z-scores. A 1-unit decrease in the telomere Z-score was associated with 0.47 more structural abnormalities ( $p=0.018,95 \%$ confidence interval [Cl] 0.09-0.85). (B) Neurologic manifestations and telomere length Z-scores. A 1-unit decrease in the telomere Z-score was associated with 0.89 more neurologic abnormalities ( $p<0.001,95 \% \mathrm{Cl} 0.42-1.35)$. in 1 sibling each in sibling pairs with disease due to TINF2 and 1 with $\mathrm{DKC1}$.

\section{Discussion}

In addition to the classic mucocutaneous triad and high rates of BMF, patients with $\mathrm{DC}$ and related TBDs may have complex structural brain abnormalities, neurodevelopmental disorder, neuromotor impairment, and/or psychiatric diagnoses that can complicate their diagnosis and management. In a 2011 review of 118 patients with DC, features reported were developmental delay in $25 \%$, ataxia/cerebellar hypoplasia in $7 \%$, and microcephaly in $6 \%{ }^{6}$ We previously reported on 10 patients with DC and found that $70 \%$ had a primary psychiatric disorder and $30 \%$ had developmental delay. $^{8}$ In our current study, we report structural brain abnormalities in addition to neurologic and psychiatric manifestations at higher frequencies than previously reported and that these phenotypes are associated with inheritance patterns, telomere length, and degree of BMF.

All patients with TBDs have very short telomeres for their age compared with unaffected individuals. ${ }^{5,14} \mathrm{We}$ found the shortest telomeres in patients with more structural brain findings and neurologic abnormalities than in patients with TBD with a normal brain MRI. Children with $\mathrm{DC}, \mathrm{HH}$, or RS and disease due to XLR or AR inheritance or de novo TINF2 mutations were more likely to have CNS manifestations, including structural brain abnormalities (primarily cerebellar hypoplasia) and the associated microcephaly, neurodevelopmental disorder, and neuromotor findings, such as ataxia. These findings are

Figure 2 Cerebellar hypoplasia exists in telomere biology disorders at varying levels of severity
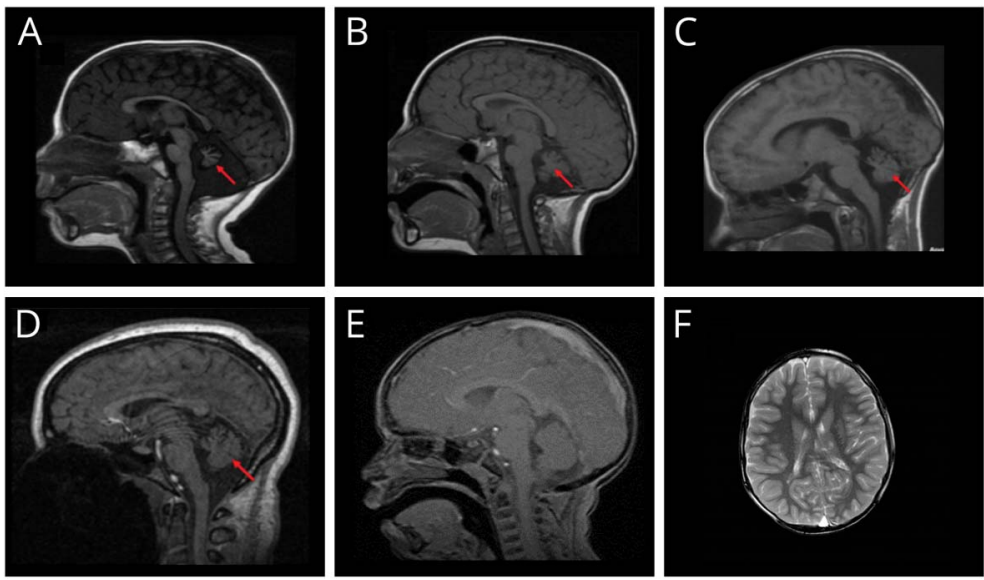

(A) Seventeen-month-old boy with heterozygous pathogenic RTEL1 variant, severe bone marrow failure, microcephaly, severe neurodevelopmental disorder, and truncal ataxia. (B) Three-year-old affected brother of A with mild cytopenia, microcephaly, ataxia, and global neurodevelopmental and speech disorders. (C) Ten-year-old boy with pathogenic DKC1 variant. He had the mucocutaneous triad, microcephaly, esophageal and meatal strictures, incoordination, and progressive bone marrow failure needing treatment by age 10 years. (D) Normal cerebellum and mild prominence of cisterna magna in a 15-year-old girl with dyskeratosis congenita (DC) due to TERC pathogenic variant. (E) Normal size cerebellum and cisterna magna in a 3-year-old boy with DC due to TINF2 pathogenic variant. (F) Bilateral periventricular cystic leukomalacia adjacent to the ventricular trigones in a 6-year-old boy with TINF2 pathogenic variant. Arrow indicates cerebellar abnormalities. 
Table 3 Incidental findings on brain imaging in the general pediatric population in comparison with brain MRI findings in patients with TBDs

\begin{tabular}{|c|c|c|c|}
\hline & \multirow{2}{*}{$\begin{array}{l}\mathrm{NCl} \text { cohort } \\
\text { Patients with } \\
\text { TBDs }(\mathrm{n}=44)\end{array}$} & \multicolumn{2}{|c|}{ Jansen et al. ${ }^{16}$} \\
\hline & & $\begin{array}{l}\text { Children } \\
(n=3,966)\end{array}$ & $p$ Value \\
\hline \multicolumn{4}{|l|}{ MRI abnormalities } \\
\hline $\begin{array}{c}\text { Corpus callosum } \\
\text { abnormalities }\end{array}$ & 8 & 2 & $<0.0001$ \\
\hline $\begin{array}{l}\text { Hamartoma or low-grade } \\
\text { glioma }^{\mathrm{a}}\end{array}$ & 1 & 4 & 0.05 \\
\hline Chiari I malformation & 1 & 25 & 0.25 \\
\hline \multicolumn{4}{|l|}{ Other MRI findings } \\
\hline $\begin{array}{l}\text { Prominent cisterna } \\
\text { magna }\end{array}$ & 11 & 104 & $<0.0001$ \\
\hline Arachnoid cyst & 2 & 86 & 0.25 \\
\hline Pineal gland cyst & 3 & 665 & 0.10 \\
\hline White matter lesion & 7 & 8 & $<0.0001$ \\
\hline $\begin{array}{l}\text { Cavum septum } \\
\text { pellucidum and/or } \\
\text { cavum vergae }\end{array}$ & 20 & 79 & $<0.0001$ \\
\hline
\end{tabular}

Abbreviation: $\mathrm{NCl}=$ National Cancer Institute; $\mathrm{TBD}=$ telomere biology disorder.

Comparison with the frequencies reported in a pediatric population is reported on the total TBD cohort, and $p$ values are computed with the Fisher exact test.

a It was not possible to distinguish hamartoma from glioma in the thalamus based on MRI in this case.

consistent with previous studies suggesting more clinical complications in patients with TBDs due to recessive or TINF2 disease and that these genetic etiologies result in exceedingly short telomeres. ${ }^{14,15}$ Notably, there were fewer abnormal brain MRI findings in adult patients with TBDs, possibly due to the fact that patients with $\mathrm{AD}$ TBDs often present as adults with isolated disease, such as pulmonary fibrosis or aplastic anemia. ${ }^{17}$ It is notable that psychiatric disorders, including depression and anxiety, were present in 8 of the $18(44 \%)$ adults, a rate higher than reported in the general population. ${ }^{18}$

In comparison with the reported incidental findings on MRI in a general pediatric population, patients with $\mathrm{DC}, \mathrm{HH}$, or $\mathrm{RS}$ had higher frequencies of corpus callosum abnormalities, prominent cisterna magna, white matter lesions, and cavum septum pellucidum and/or cavum vergae. ${ }^{16}$ Certain findings reported in the general population were not present in our cohort, likely because of its small sample size. For example, we had no patients with heterotopia, cortical dysplasia, agenesis of the septum pellucidum, or porencephalic cyst.

The role of telomere biology in brain development has been evaluated in a conditional knockout of the shelterin protein TRF2 mouse model. ${ }^{19}$ By knocking out TRF at different stages of neuronal differentiation, the authors showed that intact telomeres are essential for embryonic and adult neurogenesis. Specifically, TRF2 knockout resulted in uncapping of telomeres and a small dentate gyrus due to loss of granule cells in the hippocampus. However, conditional knockout of TRF2 in postmitotic neurons did not have an appreciable effect on cell function or animal behavior. Of interest, there are 5 reported cases of patients with $\mathrm{HH}$ and hypoplasia of the granular layer. $^{20-23}$

Our data support the hypothesis that aberrant telomere biology affects brain development, possibly through a combination of differences in neuronal connectivity and related structural differences. We also hypothesize that the cerebellum may be particularly vulnerable to aberrant telomere biology because it divides very early in development and for a longer time relative to other areas of the brain. ${ }^{24}$ Because more cell divisions are required for cerebellar development and telomeres shorten with each cell division, it is possible that the cerebellar precursor cells in the fetus do not have the replicative capacity to proliferate normally due to exceedingly short telomeres in fetuses with $\mathrm{DC}, \mathrm{HH}$, and RS, thus explaining the relatively more common and more severe abnormalities in the cerebellum vs the less common, more minor anomalies in the cerebrum.

The current study is the first to systematically review brain MRIs in a series of patients with DC, HH, and RS. All brain MRIs were reviewed by the same neuroradiologist and the same subspecialty clinical teams evaluated the patients. An additional strength of our study is that MRIs were conducted independent of clinical indication, allowing for better estimates of the true prevalence of these findings in these disorders than has been previously reported. However, our study may not reflect the full spectrum of TBD-related neurologic complications because pediatric patients with especially severe manifestations are likely overrepresented in our study. A limitation of our study is that the brain MRIs varied in both quality and technique, as MRI technology advanced during the course of the study and images were acquired from several institutions. This lack of consistency may have led to the possibility of false negatives in some of the MRI reports, creating detection bias within our results. The data used in this study were cross-sectional; future studies involving prospective and longitudinal data are needed to further elucidate genotype-phenotype relationships in TBDs. Longitudinal MRI data are especially important when assessing delayed myelination $^{25}$; cross-sectional studies of brain MRIs from older children and adults do not provide information about delayed myelination occurring during early development. Thus, the cross-sectional nature of our data did not allow us to estimate the prevalence of abnormal myelination in relation to developmental abnormalities in patients with TBDs. However, the high frequency of minor colpocephaly, which is associated with white matter abnormalities in the posterior cerebrum, suggests that white matter development may be affected $^{26}$ in patients with TBDs and needs to be further studied. 

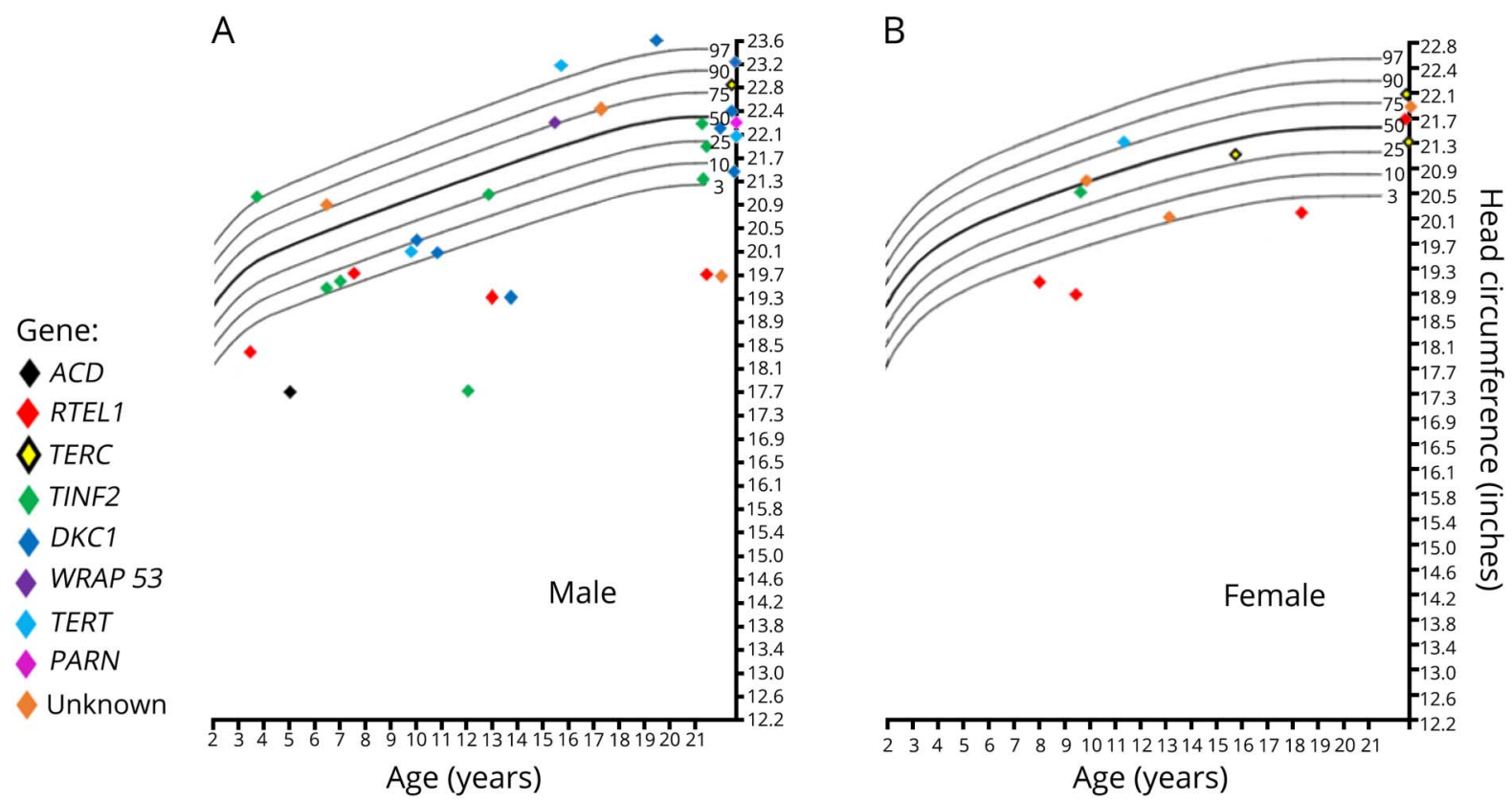

(A) Males. (B) Females. There was also one 19-month-old patient in the study with microcephaly who is not shown because of lack of exact measurements.

This study shows that structural brain abnormalities and clinically significant neurologic and psychiatric disorders are common in patients with TBDs. This report illustrates the need for research on the role of telomere biology in neurodevelopment. Comprehensive neurologic, neuropsychological, and psychiatric assessments and baseline brain MRI are indicated in patients with $\mathrm{DC}, \mathrm{HH}$, and RS to facilitate early referral to neurodevelopmental and mental health services.

\section{Author contributions}

S. Bhala: study design, data collection, data analysis, data interpretation, and writing. A.F. Best: study design, data analysis, and writing. N. Giri: study design, data collection, data analysis, data interpretation, and writing. B.P. Alter: study design, data collection, data interpretation, and writing. M. Pao: data collection, data interpretation, and writing. A. Gropman and E.H. Baker: study design, data collection, data interpretation, and writing. S.A. Savage: study design, data collection, data analysis, data interpretation, and writing.

\section{Acknowledgment}

The authors are grateful to thank all patients and their family members for making this work possible. They also thank the referring physicians, the MRI technologists who acquired the images, and Lisa Leathwood, RN, Maureen Risch, RN, and Ann Carr, CGC, of Westat, Inc. for clinical support.

\section{Study funding}

This work was funded by the Intramural Research Programs of the Division of Cancer Epidemiology and Genetics, National
Cancer Institute, NIH, the National Institute of Mental Health (ZIA MH002922-11), NIH, and the NIH Clinical Center.

\section{Disclosure}

Disclosures available: Neurology.org/NG.

\section{Publication history}

Received by Neurology: Genetics April 26, 2019. Accepted in final form September 23, 2019.

\section{References}

1. Savage SA. Beginning at the ends: telomeres and human disease. F1000Res 2018;7

2. Bertuch AA. The molecular genetics of the telomere biology disorders. RNA Biol 2016;13:696-706.

3. Dokal I, Vulliamy T, Mason P, Bessler M. Clinical utility gene card for: dyskeratosis congenita-update 2015. Eur J Hum Genet 2015;23.

4. Alter BP, Giri N, Savage SA, Rosenberg PS. Cancer in dyskeratosis congenita. Blood 2009;113:6549-6557.

5. Alter BP, Baerlocher GM, Savage SA, et al. Very short telomere length by flow fluorescence in situ hybridization identifies patients with dyskeratosis congenita. Blood 2007; 110:1439-1447.

6. Dokal I. Dyskeratosis congenita. Hematol Am Soc Hematol Educ Program 2011; 2011:480-486.

7. Vulliamy T, Dokal I. Dyskeratosis congenita. Semin Hematol 2006;43:157-166.

8. Rackley S, Pao M, Seratti GF, et al. Neuropsychiatric conditions among patients with dyskeratosis congenita: a link with telomere biology? Psychosomatics 2012;53:230-235

9. Alter BP, Giri N, Savage SA, et al. Malignancies and survival patterns in the National Cancer Institute inherited bone marrow failure syndromes cohort study. $\mathrm{Br} \mathrm{J}$ Haematol 2010;150:179-188.

10. Alter BP, Giri N, Savage SA, Rosenberg PS. Cancer in the National Cancer Institute inherited bone marrow failure syndrome cohort after fifteen years of follow-up. Haematologica 2018;103:30-39.

11. (CDC) CfDCaP. Facts about microcephaly [online]. Available at: cdc.gov/ncbddd/ birthdefects/microcephaly.html. Accessed July 2, 2018.

12. Diagnostic and Statistical Manual of Mental Disorders. 4th ed. Washington, DC: American Psychiatric Association, 2000.

13. Diagnostic and Statistical Manual of Mental Disorders, 5th ed. Washington, DC: American Psychiatric Association, 2013.

14. Alter BP, Rosenberg PS, Giri N, Baerlocher GM, Lansdorp PM, Savage SA. Telomere length is associated with disease severity and declines with age in dyskeratosis congenita. Haematologica 2012;97:353-359. 
15. Ward SC, Savage SA, Giri N, et al. Beyond the triad: inheritance, mucocutaneous phenotype, and mortality in a cohort of patients with dyskeratosis congenita. J Am Acad Dermatol 2018;78:804-806.

16. Jansen PR, Dremmen M, van den Berg A, et al. Incidental findings on brain imaging in the general pediatric population. N Engl J Med 2017;377:1593-1595.

17. Savage SA, Alter BP. Dyskeratosis congenita. Hematology/oncology Clin North America 2009;23:215-231.

18. Health NIoM. Mental illness [online]. Available at: nimh.nih.gov/health/statistics/ mental-illness.shtml. Accessed January 20, 2019.

19. Lobanova A, She R, Pieraut S, Clapp C, Maximov A, Denchi EL. Different requirements of functional telomeres in neural stem cells and terminally differentiated neurons. Genes Dev 2017;31:639-647.

20. Hoyeraal HM, Lamvik J, Moe PJ. Congenital hypoplastic thrombocytopenia and cerebral malformations in two brothers. Acta Paediatr Scand 1970;59: $185-191$.
21. Hreidarsson S, Kristjansson K, Johannesson G, Johannsson JH. A syndrome of progressive pancytopenia with microcephaly, cerebellar hypoplasia and growth failure. Acta Paediatr Scand 1988;77:773-775.

22. Mahmood F, King MD, Smyth OP, Farrell MA. Familial cerebellar hypoplasia and pancytopenia without chromosomal breakages. Neuropediatrics 1998;29:302-306.

23. Berthet F, Caduff R, Schaad UB, et al. A syndrome of primary combined immunodeficiency with microcephaly, cerebellar hypoplasia, growth failure and progressive pancytopenia. Eur J Pediatr 1994;153:333-338.

24. Tiemeier H, Lenroot RK, Greenstein DK, Tran L, Pierson R, Giedd JN. Cerebellum development during childhood and adolescence: a longitudinal morphometric MRI study. Neuroimage 2010;49:63-70.

25. Branson HM. Normal myelination: a practical pictorial review. Neuroimaging Clin $\mathrm{N}$ Am 2013;23:183-195.

26. Barkovich AJ, Lyon G, Evrard P. Formation, maturation, and disorders of white matter. AJNR Am J Neuroradiol 1992;13:447-461. 


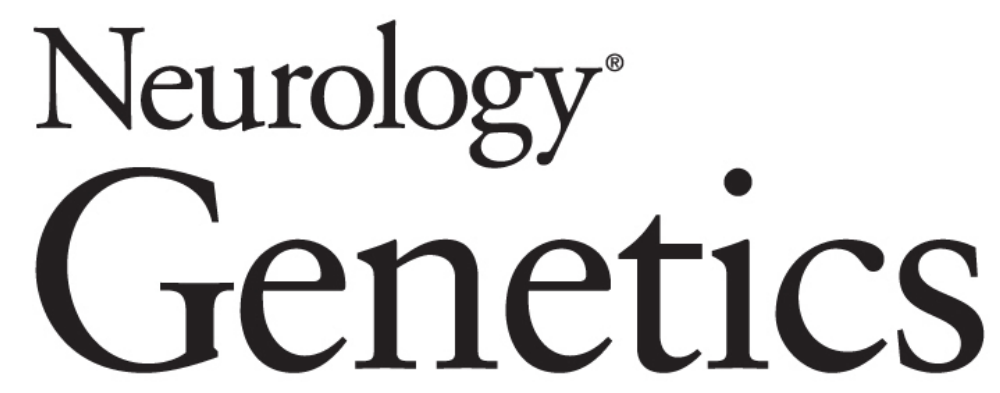

CNS manifestations in patients with telomere biology disorders

Sonia Bhala, Ana F. Best, Neelam Giri, et al.

Neurol Genet 2019;5;

DOI 10.1212/NXG.0000000000000370

This information is current as of October 29, 2019

Updated Information \&
Services

References

Subspecialty Collections

Permissions \& Licensing

Reprints including high resolution figures, can be found at: http://ng.neurology.org/content/5/6/370.full.html

This article cites 20 articles, 6 of which you can access for free at: http://ng.neurology.org/content/5/6/370.full.html\#\#ref-list-1

This article, along with others on similar topics, appears in the following collection(s):

All Genetics

http://ng.neurology.org//cgi/collection/all_genetics

All Psychiatric disorders

http://ng.neurology.org//cgi/collection/all_psychiatric_disorders

Developmental disorders

http://ng.neurology.org//cgi/collection/developmental_disorders

Information about reproducing this article in parts (figures,tables) or in its entirety can be found online at:

http://ng.neurology.org/misc/about.xhtml\#permissions

Information about ordering reprints can be found online:

http://ng.neurology.org/misc/addir.xhtml\#reprintsus

Neurol Genet is an official journal of the American Academy of Neurology. Published since April 2015, it is an open-access, online-only, continuous publication journal. Copyright Copyright @ 2019 The Author(s). Published by Wolters Kluwer Health, Inc. on behalf of the American Academy of Neurology.. All rights reserved. Online ISSN: 2376-7839.

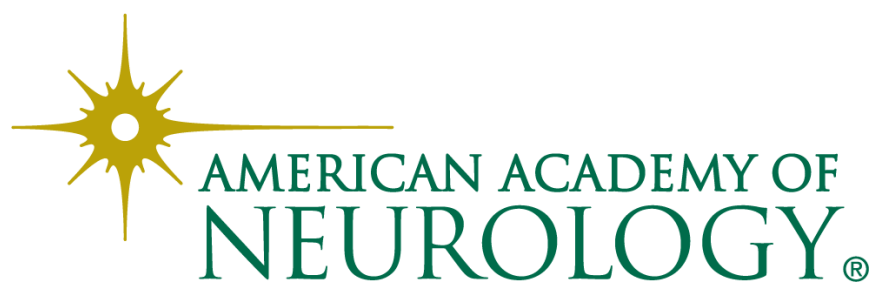

